\title{
PRIMARY PRODUCTION OF THE CENTRAL GRASSLAND REGION OF THE UNITED STATES ${ }^{1,3}$
}

\author{
O. E. Sala, ${ }^{2}$ W. J. Parton, L. A. Joyce, and W. K. Lauenroth \\ Natural Resource Ecology Laboratory and Range Science Department, Colorado State University, and \\ Rocky Mountain Forest and Range Experiment Station, United States Department of Agriculture \\ Forest Service, Fort Collins, Colorado 80523 USA
}

\begin{abstract}
Aboveground net primary production of grasslands is strongly influenced by the amount and distribution of annual precipitation. Analysis of data collected at 9500 sites throughout the central United States confirmed the overwhelming importance of water availability as a control on production. The regional spatial pattern of production reflected the east-west gradient in annual precipitation. Lowest values of aboveground net primary production were observed in the west and highest values in the east. This spatial pattern was shifted eastward during unfavorable years and westward during favorable years. Variability in production among years was maximum in northern New Mexico and southwestern Kansas and decreased towards the north and south. The regional pattern of production was largely accounted for by annual precipitation. Production at the site level was explained by annual precipitation, soil water-holding capacity, and an interaction term. Our results support the inverse texture hypothesis. When precipitation is $<370 \mathrm{~mm} / \mathrm{yr}$, sandy soils with low water-holding capacity are more productive than loamy soils with high waterholding capacity, while the opposite pattern occurs when precipitation is $>370 \mathrm{~mm} / \mathrm{yr}$.

Key words: Central Grassland region; inverse texture effect; precipitation effect; primary production; production controls; scaling; soil texture effect; spatial pattern; temporal variability; water use efficiency.
\end{abstract}

\section{INTRODUCTION}

The Central Grassland region of the United States of America extends from the deciduous forest on the east to the Rocky Mountains on the west, and from the Canadian to the Mexican borders. This region encompasses a wide variety of climatic conditions; precipitation ranges from 260 to $1200 \mathrm{~mm}$ and annual average temperature ranges from $3^{\circ}$ to $22^{\circ} \mathrm{C}$. Despite the large differences in climate, the potential natural vegetation of the region is largely grassland (Küchler 1964). Four types of grassland occur within the region: the northern and southern mixed prairies, the tallgrass prairie, and the shortgrass steppe (Risser et al. 1981, Singh et al. 1983).

Estimates of aboveground net primary production (ANPP) have been reported for many sites in the Central Grassland region as well as around the world (Lauenroth 1979). In each case, estimates of ANPP were from single sites. A small number of studies provide information about the temporal dynamics of productivity (Sims and Singh 1978). This paper focuses on the spatial distribution of ANPP over the entire Central Grassland region. Data collected at 9500 sites were analyzed at the individual site level, and then

\footnotetext{
' Manuscript received 6 June 1986; revised 15 April 1987; accepted 4 May 1987.

${ }^{2}$ On leave from Department of Ecology, Faculty of Agronomy, University of Buenos Aires, Av. San Martín 4453, Buenos Aires 1417, Argentina.

${ }^{3}$ Send reprint requests to W. K. Lauenroth.
}

grouped into major land resource areas (MLRA) (USDA, SCS 1981) and analyzed at the regional level.

We had two objectives for the analysis at the regional level. The first was to evaluate the spatial and temporal pattern of annual production for the region. While no such analysis has been attempted for the grassland region, similar analyses have been conducted for other regions (Rodin et al. 1975, Sharp et al. 1975, Sharpe 1975, Box 1978, Meentemeyer 1984). Our second objective at the regional level was to evaluate the importance of climatic variables as determinants of the pattern of primary production at the MLRA level. Rosenzweig (1968) and Lieth (1975) developed models that related primary production on a global basis to precipitation and temperature. Both models have similar structures, but Rosenzweig used actual evapotranspiration as the independent variable, while Lieth utilized annual precipitation and annual temperature. Webb et al. $(1978,1983)$ analyzed primary production data from three biomes in North America: forests, grasslands, and deserts. They found that precipitation and potential evapotranspiration accounted for a large fraction of the variance of ANPP in grasslands and deserts, while radiation was the most important variable in explaining forest ANPP. Lauenroth (1979) studied the controls of primary production solely for grasslands, but on a global scale. He presented a model in which primary production was explained by annual precipitation over a range from 150 to $1800 \mathrm{~mm} / \mathrm{yr}$. The model had a better fit towards the dry end of the 

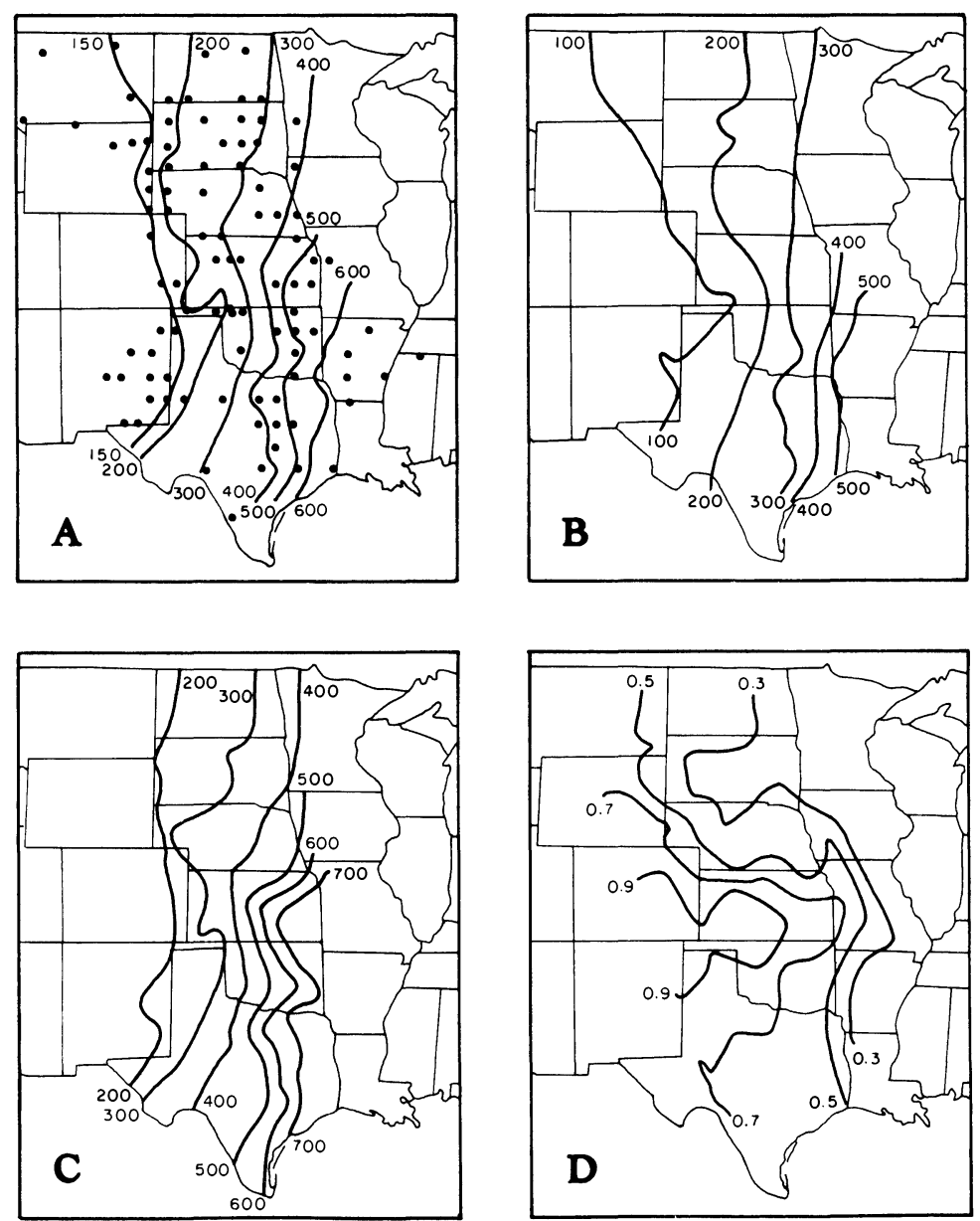

FIG. 1. Isopleths of aboveground net primary production (ANPP, $g / \mathrm{m}^{2}$ ) for the Central Grassland region (A) during years of average precipitation, (B) during unfavorable years, and (C) during favorable years. (D) isopleths of relative variability in production between favorable and unfavorable years estimated as

(production favorable) - (production unfavorable) average production

Dots represent the location of the center of the state portions of major land resource areas (MLRA). Each state portion of the MLRA was treated as a separate unit where an MLRA crossed a state boundary.

precipitation range than towards the wet end, where water availability is less frequently the limiting factor.

Our objective for the site level analysis was to evaluate the interaction between climate and soil variables as determinants of primary production. We hypothesized that soil characteristics are important in explaining production at the site level but are overshadowed by climate at the regional level. Since primary production in grasslands is frequently limited by water availability (Lauenroth 1979), we selected water-holding capacity as the soil characteristic to explain the production pattern at the site level. Water-holding capacity along with precipitation pattern are the major determinants of soil water availability for plants (Jenny 1980). We wanted to test the inverse texture hypothesis (Noy-Meir 1973), which states that production in dry regions should be greater on coarse-texture (low water- holding capacity) soils than on fine-texture (high waterholding capacity) soils.

\section{METHODS}

Our study was based on a data set collected by the USDA Soil Conservation Service at 9498 sites throughout the Central Grassland region of the United States (Joyce et al. 1986). For each site, the database contains estimates of primary production for favorable, unfavorable, and average years, as well as a description of the soil profile that includes texture of the A horizon.

Primary production included the aboveground parts of all plants (except mosses and lichens) produced during a single growth year, regardless of accessibility to grazing animals (USDA, SCS 1976). Primary production estimates were obtained by the double-sampling 
procedure (Wilm et al. 1944). At least one plot was harvested for each seven estimated. A minimum of 10 plots and a maximum of 20 were estimated per site depending upon the spatial heterogeneity of the vegetation. Minimum plot size was $17.8 \mathrm{dm}^{2}$. An $89.2-\mathrm{dm}^{2}$ plot was used in areas where production was relatively low. Production was expressed as air-dry matter in grams per square metre. Measurements were done in sites not grazed during the current growing season.

Favorable and unfavorable years were defined based upon long-term frequency distributions of precipitation (USDA, SCS 1973). Favorable years were defined as the wettest $10 \%$ of the years in the record, and the unfavorable years were defined as the driest $10 \%$ of the years. Production was estimated for favorable, average, and unfavorable years (USDA, SCS 1976).

The regional pattern of ANPP was analyzed by grouping sites into 100 areas that represent the major land resource areas (MLRA) within each state, as defined by the Soil Conservation Service (USDA, SCS 1981). The average of the ANPP of all the sites within a state's MLRA determined its ANPP. Long-term averages of monthly temperature and precipitation were retrieved for locations near the geographical center (Fig. 1A) of each MLRA (United States Weather Bureau 1964). Using this information, we calculated annual and growing-season values of potential evapotranspiration (Linacre 1977), temperature, precipitation, and the precipitation/potential evapotranspiration ratio.

We constructed isopleths of production using MLRA data, with a contour interval of $100 \mathrm{~g} / \mathrm{m}^{2}$ for favorable, average, and unfavorable years. The importance of climatic variables as determinants of the pattern of primary production at the MLRA level was evaluated by multiple regression analysis between ANPP and different climatic variables. Soil water-holding capacity for each of the 9498 sites was estimated from soil texture information (A. J. Erickson, personal communication). Soil water-holding capacity depends foremost on the texture of a soil (Jenny 1980). The controls of primary production at the site level were evaluated by multiple regression analysis between ANPP estimates and soil water-holding capacity and climatic variables.

\section{RESULTS AND DISCUSSION}

The spatial pattern of average aboveground net primary production for the Central Grassland region has a dominant east-west gradient (Fig. 1A). This pattern of production is very similar to the isohyet pattern (Borchert 1950). In the northern portion of the region, the $200 \mathrm{~g} / \mathrm{m}^{2}$ isopleth runs in a north-south direction. We observed that west of this isopleth production increases towards the north. In contrast, east of this line production decreases northward. We speculate that in the humid portion, decreasing temperatures and length of growing season limit production. In the dry portion, decreasing temperatures result in a reduction of evapotranspiration and an increase in available water. Dur- ing average years, ANPP ranges from $150 \mathrm{~g} / \mathrm{m}^{2}$ in the west to $600 \mathrm{~g} / \mathrm{m}^{2}$ in the southeastern portion of the region.

Production during unfavorable years is characterized by an eastward shift in the spatial pattern (Fig. 1B). The $200 \mathrm{~g} / \mathrm{m}^{2}$ isopleth shifts $\approx 2^{\circ}$ longitude in unfavorable years compared to average years. Production during favorable years is characterized by a westward shift in the spatial pattern (Fig. 1C). The $200 \mathrm{~g} / \mathrm{m}^{2}$ isopleth shifts to the west, following the eastern edge of the Rocky Mountains, and the range in production increases compared to average years. From unfavorable to favorable years the ANPP isopleths shift from east to west, but their shape remains approximately the same.

Unfavorable years correspond to drought years, which are associated with a decrease in the normal flow of air from the Gulf of Mexico during the summer months and a predominance of westerlies throughout the year. Because droughts are the consequence of changes in the large-scale pattern of atmospheric circulation, they affect the entire grassland region (Borchert 1950).

The variability in production among years, estimated as the relative difference between favorable and unfavorable years $\frac{\text { (favorable }- \text { unfavorable) }}{\text { average }}$, has a distinct regional pattern (Fig. 1D). Isopleths of variability have the approximate shape of concentric wedges with the center in southwest Kansas. Maximum variability occurs in the region that extends from northern New Mexico to southwestern Kansas. Variability decreases towards the north and south of this area. The shape of the area where variability is higher than $80 \%$ coincides with Borchert's (1950) wedge of spring and summer rainfall deficiency, characteristic of major drought years across the Central United States. His analysis showed the occurrence of this wedge-shaped area in which precipitation rapidly decreased towards the center during drought years. Outside the wedge, precipitation tended to be near or above normal during these years.

The pattern of production at the MLRA level is largely accounted for by annual precipitation (Fig. 2). For average years the model is ANPP $=-34+0.6 \cdot \mathrm{APPT}$, $r^{2}=0.90 ; F_{1,98}=935, P<.01$, where ANPP is annual aboveground net primary production in grams per square metre and APPT is annual precipitation in millimetres. Addition of other climatic variables such as potential evapotranspiration, temperature, or the precipitation: potential evapotranspiration ratio for the growing season or the entire year did not improve the model. None of the more complicated models accounted for $>90 \%$ of the variance in production. Our simple model can be written in the form of Noy-Meir's (1973) model:

$$
\mathrm{ANPP}=0.6 \cdot(\mathrm{APPT}-56),
$$

where 0.6 represents the average water-use efficiency 


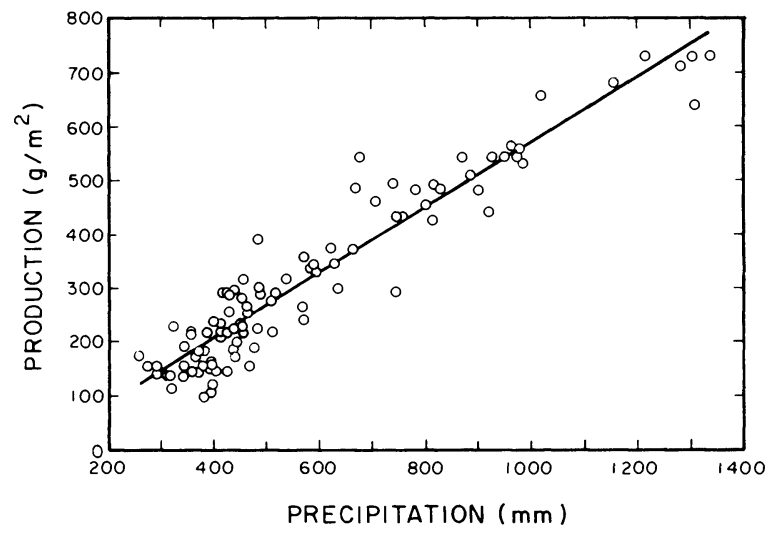

FIG. 2. Relationship between mean annual precipitation and mean aboveground net primary production (ANPP) for 100 major land resource areas across the Central Grassland region. ANPP $=-34+0.6 \cdot \mathrm{APPT} ; r^{2}=0.90$.

of the community (dry matter: $\mathrm{g} \cdot \mathrm{m}^{-2} \cdot \mathrm{mm}^{-1}$ of precipitation) and $56(\mathrm{~mm} / \mathrm{yr})$ is the "ineffective precipitation," or "zero-yield intercept." Our efficiency value for the Central Grassland region lies within the range originally proposed by Noy-Meir (1973) $\left(0.5-2 \mathrm{~g} \cdot \mathrm{m}^{-2} \cdot \mathrm{mm}^{-1}\right)$ and closely agrees with the efficiency reported by other authors (Lauenroth 1979, Rutherford 1980, Le Houérou 1984). Our value for ineffective precipitation is higher than Lauenroth's (1979) $(29 \mathrm{~mm} / \mathrm{yr})$ but lies within the range proposed by Noy-Meir (1973) (25-75 mm/yr). Some of the previous models implicitly set an upper limit on production (Whittaker 1970, Lieth 1975, Webb et al. 1978). For our production data, which ranged between 100 and $700 \mathrm{~g} / \mathrm{m}^{2}$, inclusion of an upper limit did not improve the fit of the model (Fig. 2). We expect that our simple model will not be useful for regions with a higher precipitation regime, where production is mostly limited by light or nutrients.

Production at the site level was analyzed using information from the 9498 sites. Variability in production of sites was accounted for by annual precipitation and soil water-holding capacity. Our models are

Average years:

$$
\begin{aligned}
\mathrm{ANPP}= & 32+(0.45 \cdot \mathrm{APPT})-(352 \cdot \mathrm{WHC}) \\
& +(0.95 \cdot \mathrm{WHC} \cdot \mathrm{APPT}) \\
R^{2}= & 0.67 ; \quad F_{3.9483}=6630 ; \quad P<.01
\end{aligned}
$$

Favorable years:

$$
\begin{aligned}
\mathrm{ANPP}= & 80+(0.51 \cdot \mathrm{APPT})-(327 \cdot \mathrm{WHC}) \\
& +(0.94 \cdot \mathrm{WHC} \cdot \mathrm{APPT}), \\
R^{2}= & 0.60 ; \quad F_{3,9483}=4746 ; \quad P<.01
\end{aligned}
$$

Unfavorable years:

$$
\begin{aligned}
\mathrm{ANPP}= & -7.2+(0.38 \cdot \mathrm{APPT})-(415 \cdot \mathrm{WHC}) \\
& +(1.01 \cdot \mathrm{WHC} \cdot \mathrm{APPT}), \\
R^{2}= & 0.68 ; \quad F_{3,9483}=6705 ; \quad P<.01,
\end{aligned}
$$

where WHC is soil water-holding capacity, which ranges from 0.05 to 0.2 water as a proportion of soil dry mass. The three models show that production increases with precipitation and that soil water-holding capacity can have a positive or negative slope depending upon the precipitation value. The model for average years predicts that, when annual precipitation is $<370 \mathrm{~mm}$, sandy soils with low water-holding capacity will be more productive than loamy soils with high waterholding capacity (Fig. 3). When precipitation is $>370$ $\mathrm{mm}$, the model predicts that sandy soils will be less productive than loamy soils. The relationship between the values observed and predicted by the model gives an indication of the spread of the raw data (Fig. 4). Data points were uniformly distributed and no characteristic departure from the model was observed.

Our data and models support the inverse texture hypothesis (Noy-Meir 1973) and yield and estimation of the point at which there is no texture effect. This is the first data set that is broad enough to test this hypothesis for grasslands. Gaines et al. (1954) reported increased forage production from deep sands to clayey soils for a site near the more humid end of our range. Le Houérou (1984) found that with precipitation $<300$ $\mathrm{mm} / \mathrm{yr}$, olive yield in the arid zone of Tunisia was higher on sandy soils than on silty soils. The opposite pattern was found when precipitation was higher than $300 \mathrm{~mm} / \mathrm{yr}$.

The explanation for the interaction between precip-

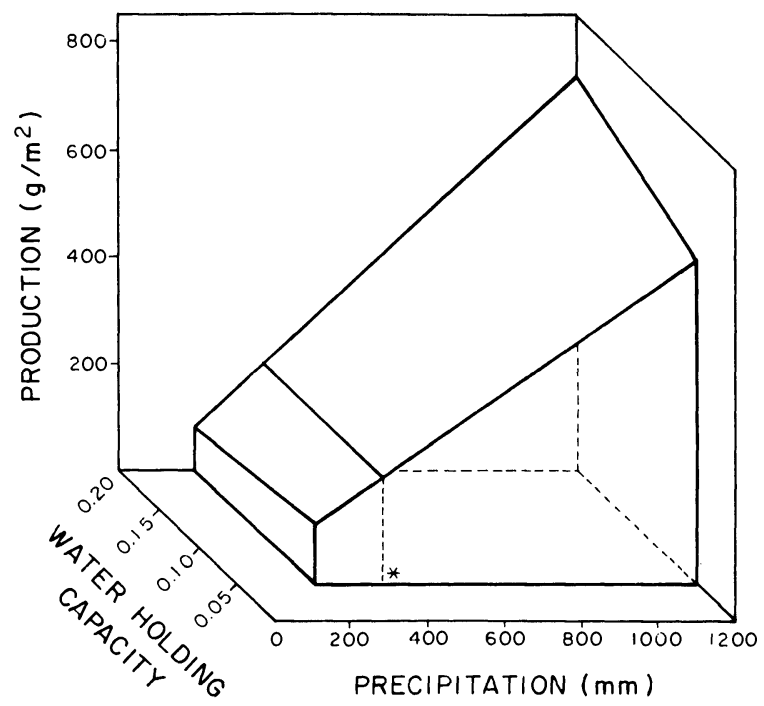

FIG. 3. Relationship between aboveground net primary production (ANPP) during average years, soil water-holding capacity (WHC, as a proportion of soil dry mass), and mean annual precipitation for 9498 sites across the Central Grassland region. At $370 \mathrm{~mm}$ of precipitation (*), soil water-holding capacity does not modify primary production. Above this value, primary production increases with increasing waterholding capacity. Below $370 \mathrm{~mm}$ of precipitation, primary production decreases with increasing water-holding capacity. $\mathrm{ANPP}=32+0.45 \cdot \mathrm{APPT}-352 \cdot \mathrm{WHC}+0.95 \cdot \mathrm{WHC} \cdot \mathrm{APPT}$; $R^{2}=0.67$. 


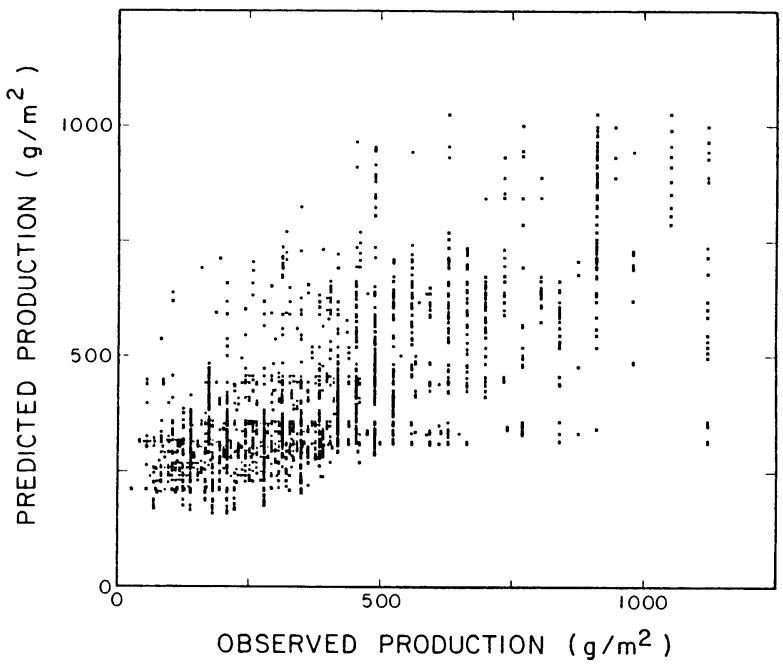

FIG. 4. Relationship between the observed values of production and the values predicted by the site level model for average years.

itation and soil water-holding capacity is related mainly to the dynamics of soil water. In dry regions, major losses of soil water occur via bare soil evaporation. However, where sandy soils occur, bare soil evaporation is lower than in loamy soils because water penetrates deeper into the soil. Runoff also is lower in sandy soils than in loamy soils (Buckman and Brady 1960). In more humid regions, substantial water losses occur via deep percolation, which is reduced in soils with high water-holding capacity (Noy-Meir 1973). Therefore, in dry regions, sandy soils with low water-holding capacity have more water available for plant growth than soils with higher water-holding capacity. The opposite pattern occurs in more humid regions.

The variability in production at the site level was accounted for by two variables, annual precipitation and soil water-holding capacity. At the MLRA level only one variable (annual precipitation) was necessary to explain a large fraction of the variability in production. The better fit of a simpler model at the coarse scale was not the result of a reduction in variance, as the variance of production at the MLRA level was not statistically different $(P>.05)$ from the variance at the site level. The same response in variance due to grouping was observed for favorable, average, and unfavorable years.

We suggest that for a constant frame of reference, in our case the Central Grassland region, as the scale or analysis becomes finer, a model will need to include a larger number of variables to account for the pattern of the same process. This principle, which emerged empirically from our work, can be deduced from hierarchy theory (Allen and Starr 1982, O'Neill et al. 1986). Consequently, it should be applicable to processes other than production. The pattern of a process at a coarse scale constrains the pattern at a finer scale.
Therefore, variability at the fine scale will be accounted for by factors at this scale plus the factors that determine the pattern at the coarse scale. In the case of production, at scales finer than the individual site it will be necessary to account for additional variables such as plant species composition and grazing history.

\section{ACKNOWLEDGMENTS}

We would like to thank Caroline Yonker for helpful assistance and D. M. Schimel and C. V. Cole for invaluable discussion. This work is a contribution of the Shortgrass Steppe Long Term Ecological Research Program (NSF BSR 81-14822) and of the Great Plains Agroecosystem Project (NSF BSR 8105281).

\section{Literature Cited}

Allen, T. F. H., and T. B. Starr. 1982. Hierarchy: perspectives for ecological complexity. University of Chicago Press, Chicago, Illinois, USA.

Borchert, J. R. 1950. The climate of the central North American grassland. Annals of the Association of American Geographers 40:1-39.

Box, E. O. 1978. Geographical dimensions of terrestrial net and gross primary productivity. Radiation and Environmental Biophysics 15:305-322.

Buckman, H. O., and N. C. Brady. 1960. The nature and properties of soils. Macmillan, London, England.

Gaines, E. M., R. S. Campbell, and J. J. Brasington. 1954. Forage production on longleaf pine lands of southern Alabama. Ecology 35:59-62.

Jenny, H. 1980. The soil resource. Springer-Verlag, New York, New York, USA.

Joyce, L. A., D. E. Chalk, and A. Vigil. 1986. Range forage data base for 20 Great Plains, Southern, and Western states. United States Forest Service General Technical Report RM133

Küchler, A. W. 1964. Potential natural vegetation of the coterminous United States. American Geographical Society Special Publication 36.

Lauenroth, W. K. 1979. Grassland primary production: North American grasslands in perspective. Pages 3-24 in N. R. French, editor. Perspectives in grassland ecology. Ecological studies, Volume 32. Springer-Verlag, New York, New York, USA.

Le Houérou, H. N. 1984. Rain use efficiency: a unifying concept in arid-land ecology. Journal of Arid Environments 7:213-247.

Lieth, H. 1975. Modeling the primary productivity of the world. Pages 237-264 in H. Lieth and R. H. Whittaker, editors. Primary productivity of the biosphere. SpringerVerlag, New York, New York, USA.

Linacre, E. T. 1977. A simple formula for estimating evaporation rates in various climates, using temperature data alone. Agricultural Meteorology 18:409-424.

Meentemeyer, V. 1984. The geography of organic decomposition rates. Annals of the Association of American Geographers 74:551-560.

Noy-Meir, I. 1973. Desert ecosystems: environment and producers. Annual Review of Ecology and Systematics 4: $23-51$.

O'Neill, R. V., D. L. De Angelis, J. B. Waide, and T. F. H. Allen. 1986. A hierarchical concept of ecosystems. Princeton University Press, Princeton, New Jersey, USA.

Risser, P. G., E. C. Birney, H. D. Blocker, S. W. May, W. J. Parton, and J. A. Wiens. 1981. The true prairie ecosystem. Dowden, Hutchinson and Ross, Stroudsburg, Pennsylvania, USA.

Rodin, L. E., N. I. Bazilevich, and N. N. Rozov. 1975. Productivity of the world's main ecosystems. Pages 13-26 in 
D. E. Reichle, J. F. Franklin, and D. W. Goodall, editors. Productivity of world ecosystems. National Academy of Sciences, Washington, D.C., USA.

Rosenzweig, M. L. 1968. Net primary productivity of terrestrial communities: prediction from climatological data. American Naturalist 102:67-74.

Rutherford, M. C. 1980. Annual plant production-precipitation relations in arid and semiarid regions. South African Journal of Science 76:53-56.

Sharp, D. D., H. Lieth, and D. Whigham. 1975. Assessment of regional productivity in North Carolina. Pages 131-146 in $\mathrm{H}$. Lieth and $\mathrm{R}$. H. Whittaker, editors. Primary productivity of the biosphere. Springer-Verlag, New York, New York, USA.

Sharpe, D. M. 1975. Methods of assessing the primary production of regions. Pages 147-166 in H. Lieth and R. H Whittaker, editors. Primary productivity of the biosphere. Springer-Verlag, New York, New York, USA.

Sims, P. L., and J. S. Singh. 1978. The structure and function of ten western North American grasslands. III. Net primarv production, turnover and efficiencies of energy capture anc water use. Journal of Ecology 66:573-597.

$\rightarrow$ Singh, J. S., W. K. Lauenroth, and D. G. Milchunas. 1983. Geography of grassland ecosystems. Progress in Physical Geography 7:46-80.

USDA, SCS (United States Department of Agriculture, Soil
Conservation Service). 1973. National soils handbook. Soil Conservation Service, Washington, D.C., USA.

USDA, SCS (United States Department of Agriculture, Soil Conservation Service). 1976. National range handbook. Washington, D.C., USA.

USDA, SCS (United States Department of Agriculture, Soil Conservation Service). 1981. Land resource regions and major land resource areas of the United States. Agriculture Handbook 296. Washington, D.C., USA.

United States Weather Bureau. 1964. Climatography of the United States. United States Government Printing Office, Washington, D.C., USA.

Webb, W. L., W. K. Lauenroth, S. R. Szarek, and R. S. Kinerson. 1983. Primary production and abiotic controls in forests, grasslands, and desert ecosystems in the United States. Ecology 64:134-151.

Webb, W. L., S. Szarek, W. Lauenroth, R. Kinerson, and M. Smith. 1978. Primary productivity and water use on native forest, grassland, and desert ecosystems. Ecology 59: 1239-1247.

Whittaker, R. H. 1970. Communities and ecosystems. Macmillan, New York, New York, USA.

Wilm, H. G., D. F. Costello, and G. E. Klipple. 1944. Estimating forage yield by the double-sampling method. Journal of the American Society of Agronomy 36:193-203. 